\title{
Ocorrência de Aleurothrixus aepim (Goeldi, 1886) em mandioca na região Oeste do Paraná
}

\section{Occurrence of Aleurothrixus aepim (Goeldi, 1886) on cassava in Western Paraná \\ Vanda Pietrowski ${ }^{1 *}$, Ana Raquel Rheinheimer ${ }^{2}$, Aline Monsani Miranda', Ana Paula Gonçalves da Silva Wengrat ${ }^{1}$, Diandro Ricardo Barilli ${ }^{1}$}

\author{
Ana Paula Gonçalves da Silva Wengrat g
}

RESUMO: Este trabalho registra a ocorrência de Aleurothrixus aepim Goeldi em plantas de mandioca na região Oeste do Paraná, Brasil. A espécie foi primeiramente encontrada em fevereiro de 2009, em área experimental da Universidade Estadual do Oeste do Paraná (UNIOESTE), em folhas de mandioca da variedade fécula branca. Os exemplares foram coletados recolhendo-se folhas infestadas com ninfas de mosca-branca, caracterizadas por apresentar corpo recoberto por filamentos cerosos de coloração branca. O material foi preservado em etanol a 70\%, em frascos de vidro, e foram enviados para identificação. Novos surtos foram registrados no início de 2010 e 2011 em diferentes propriedades rurais localizadas no município de Marechal Cândido Rondon. Entretanto, a causa precisa da ocorrência de $A$. aepim nessa regiáo não está totalmente clara. Nas demais regióes produtoras do Estado, esta espécie ainda não foi detectada.

PALAVRAS-CHAVE: mosca-branca; Manihot esculenta; Aleyrodidae.

\begin{abstract}
This paper work recorded the occurrence of Aleurothixus aepim Goeldi in cassava plants in the West of Parana, Brazil. The species was first found in February, 2009, in an experimental area at Universidade Estadual do Oeste do Paraná (UNIOESTE), in cassava leaves of the white starch variety. The samples were collected by gathering leaves infested with whitefly nymphs, which are characterized for presenting body coated by white waxy filaments. The material was preserved in $70 \%$ ethanol, in glass bottles, and sent for identification. New outbreaks have been recorded in the beginning of 2010 and 2011 in different rural properties located in the city of Marechal Candido Rondon. However, the precise cause of the occurence of $A$. aepim in this region is not completely clear. In the other production regions of the State, this species has not yet been detected.
\end{abstract}

KEYWORKS: whitefly; Manihot esculenta; Aleyrodidae. 
A mandioca (Manihot esculenta Crantz) é uma cultura de grande importância social e econômica no mundo, compondo parte fundamental da alimentação de mais de 700 milhóes de pessoas, essencialmente nos países em desenvolvimento (SouzA, 2006). Além disso, apresenta papel importante como matéria prima de uma série de produtos processados (TAKahashi; Gonçalo, 2005).

O Brasil é o maior produtor de mandioca do continente sul-americano, contribuindo com $75 \%$ da produção (IBGE, 2010), gerando milhôes de empregos diretos, seja na fase de produção primária ou na de processamento, contribuindo também para a manutenção do pequeno agricultor no campo (Oliveira; Lima, 2006).

$\mathrm{Na}$ região Sul do Brasil, onde o cultivo da mandioca é destinado principalmente à comercialização das raízes para indústrias de processamento (TAKAHASHI, 2002), o Paraná destaca-se ocupando o primeiro lugar na produçáo agrícola industrial do país, respondendo em média por $60 \%$ do volume brasileiro de fécula (Groxко, 2010). Acompanhando o grande avanço tecnológico na produção, surgiram problemas com novas pragas e doenças, provavelmente devido ao desequilíbrio ambiental causado pelo uso de agroquímicos e aumento da área cultivada (TAKAHASHI, 2002).

Dentre as pragas que causam danos à cultura destacam-se as moscas-brancas, constituindo um grave problema na produçáo de mandioca (BeLlotтr et al., 1999). Pelo seu potencial de dano, neste grupo destacam-se as espécies Aleurotrachelus socialis Bondar, Bemisia tuberculata Bondar e Aleurothrixus aepim Goeldi.

Os danos são causados por ninfas e adultos, sendo caracterizados de maneira direta pela sucção da seiva, causando diminuição do vigor da planta, encarquilhamento, manchas cloróticas e queda prematura de folhas. Isso leva à redução na produtividade quando em altas populaçôes (BELlotTi et al., 2002) e, indiretamente, favorece o desenvolvimento da fumagina e a transmissão de viroses (Bellottr et al., 2002). As raízes provenientes de plantas atacadas podem também apresentar maior concentração de água e fibras, assim como sabor amargo, diminuindo seu valor comercial (Farias; Santos Filho, 1996).

No Brasil, nas áreas de cultivo de mandioca dos estados do Nordeste, predomina a espécie $A$. aepim, enquanto na regiāo Centro-Oeste ocorrem B. tuberculata e Trialeurodes variabilis Quaintance (Oliveira et al., 2001). No estado do Paraná, a espécie $B$. tuberculata está associada à cultura da mandioca (Rheinheimer et al., 2009). Porém, recentemente foi identificada na região Oeste do estado do Paraná a ocorrência de A. aepim, espécie comumente encontrada no Nordeste do país.

Nesse sentido, a presente comunicação tem por objetivo relatar a ocorrência de $A$. aepim na cultura da mandioca na regiáo Oeste do Paraná.

Em fevereiro de 2009, na área experimental da Universidade Estadual do Oeste do Paraná (UNIOESTE), no município de
Marechal Cândido Rondon (PR) (latitude de 24033'S, longitude $54^{\circ} 04^{\prime} \mathrm{W}$ e altitude de 420 metros), foram realizadas coletas de folhas de mandioca (variedade fécula branca) infestadas com moscas-brancas, caracterizadas por apresentar corpo recoberto por filamentos cerosos de coloração branca, semelhantes ao algodão (Fig. 1). Esta área fazia parte de um experimento visando coletar moscas-brancas da espécie B. tuberculata para determinar seu ciclo biológico em condiçôes de laboratório.

O material foi levado ao laboratório de Controle Biológico da UNIOESTE e, sob microscópio estereoscópico, registrou-se a presença de ovos e ninfas de mosca-branca. Parte das folhas foi acondicionada em placas de Petri contendo soluçáo de Ágar-água (3\%) para manutenção da turgidez da folha até a emergência dos adultos. Os adultos das moscas-brancas foram preservados em etanol a $70 \%$, em frascos de vidro (capacidade de $15 \mathrm{~mL}$ ), e o restante das folhas contendo ninfas dos diferentes ínstares foram armazenadas em etanol 70\% também em frascos de vidro, como descrito anteriormente, e enviados para identificaçâo em nível de espécie à Dra. Maria Del Pilar Hernandez, do Centro Internacional de Agricultura Tropical (CIAT). Após a identificação, novos surtos foram constatados no início de 2010 e 2011, em diferentes propriedades rurais localizadas no município de Marechal Cândido Rondon.

A espécie $A$. aepim já havia sido citada em diversas regióes do Nordeste do Brasil (Oliveira et al., 2001). Em Cruz das Almas (BA), sua ocorrência foi constatada em 2006 em plantas de mandioca cultivadas sob telado, na área da Embrapa Mandioca e Fruticultura Tropical, onde até então havia sido registrada apenas a incidência de $B$. tuberculata (FARIAS et al., 2007), fato similar ao ocorrido na região Oeste do Paraná. Nas demais regiōes produtoras do Estado, A. aepim ainda náo foi encontrada, ocorrendo apenas B. tuberculata.

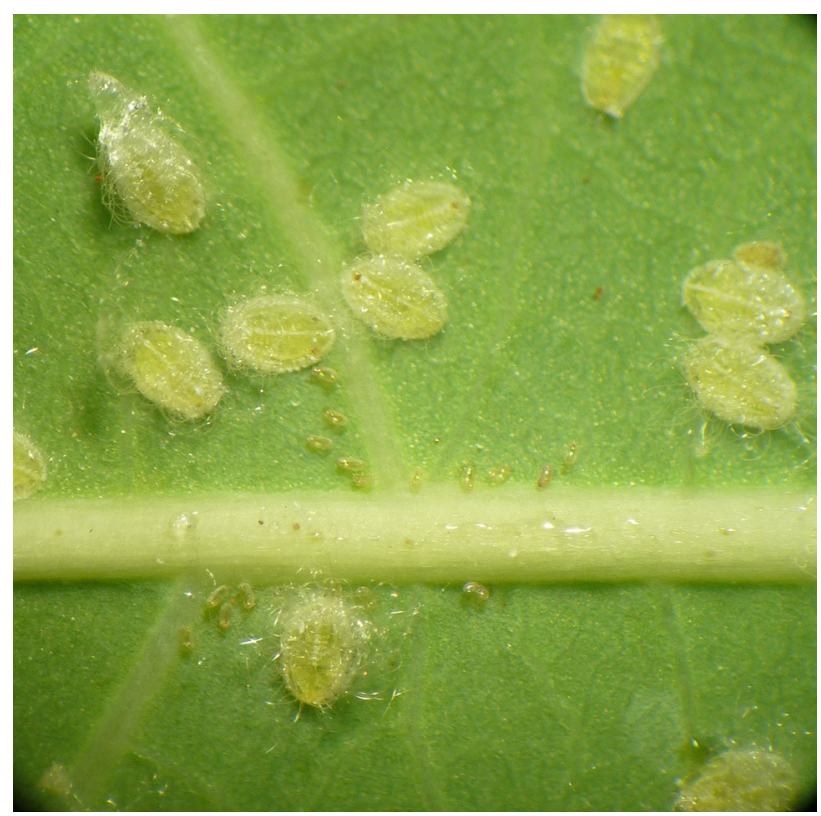

Figura 1. Ninfas de Aleurothrixus aepim. 
As causas precisas da ocorrência de $A$. aepim na região Oeste do Paraná são desconhecidas, provavelmente devido à introdução de material infestado, por ninfas e/ou adultos, de outras regióes do país.

\section{AGRADECIMENTOS}

À Dra. Maria Del Pilar Hernandez pela identificação da espécie, e à CAPES, pela concessão de bolsa de doutorado.

\section{REFERÊNCIAS}

BELLOTTI, A.C.; ARIAS, B.V.;VARGAS, O.H.; REYES, J.A.Q.; GUERRERO, J.M. Insectos y acaros dañinos a la yuca y su control. In: OSPINA, B. ; CEBALLOS, H. (Eds.) La yuca en el tercer milenio: sistemas modernos de producción, procesamiento, utilizacion y comercialización. Cali : CIAT/CLAYUCA, n.327. 2002. 586p.

BELLOTTI, A.C.; SMITH, L.; LAPOINTE, S.L. Recent advances in cassava pest management. Anais da Sociedade Entomológica do Brasil. v.44, p.343-370, 1999.

FARIAS, A.R.N.; BELLOTTI, A. C.; ALVES, A. A. C. Ocorrência de Aleurothrixus aepim (Goeldi, 1886) (Hemiptera: Aleyrodidae) em Cruz das Almas, BA. Cruz das Almas: Embrapa Mandioca e Fruticultura Tropical, 2007. 2p. (Embrapa Mandioca e Fruticultura Tropical. Circular técnica, 33). Disponível em: http://www.infoteca.cnptia. embrapa.br/handle/doc/655614. Acesso em: 02/07/2011.

FARIAS, A.R.N.; SANTOS FILHO, H.P. Controle biológico da mosca branca da mandioca com o fungo Cladosporium cladosporioides. Cruz das almas: Embrapa Mandioca e Fruticultura Tropical. 1996. 20p. (Cartilha). Disponível em: <http://www.bdpa.cnptia.embrapa.br/busca. jsp?baseDados=ACERVO\&unidade=TODAS\&fraseBusca $=\% 22 F A R$ IAS,\%2OA.\%2OR.\%20N.\%22\%20em\%2OAUT\&posicaoRegistro= 99\&formFiltroAction=N\&view=130606>. Acesso em 02 jul. 2011 .

GROXKO, M. Análise da conjuntura agropecuária safra 2009/10 mandioca. Curitiba: Secretaria da Agricultura e do Abastecimento do Paraná , 2010, 16p. Disponível em: < http://www.seab.pr.gov. $\mathrm{br} / \mathrm{modules} /$ conteudo/conteudo.php? conteudo=32>. Acesso em 01 dez. 2010.
IBGE. Instituto Brasileiro de Geografia e Estatística. Disponível em: <http://www.ibge.com.br>. Acesso em: 27 jun. 2010.

OLIVEIRA, M.R.V.; LIMA, L.H.C. Moscas-brancas na cultura da mandioca no Brasil. Brasília: Embrapa Recursos Genéticos e Biotecnológicos. 2006. 74p. (Embrapa Recursos Genéticos. Documentos, 186).

OLIVEIRA, M.R.V.; MORETZSHON, M.C.; QUEIROZ, P.R.; LAGO, W.N.M.; LIMA, L.H.C. Levantamento de moscas-brancas na cultura da mandioca no Brasil. Brasília: Embrapa Recursos Genéticos e Biotecnologia. 2001. 20p. (Embrapa Recursos Genéticos. Boletim de Pesquisa e Desenvolvimento, 31 ).

RHEINHEIMER, A.R.; BELLON, P.P; HACHMANN, T.; MIRANDA, A.M.; SCHERER, W.A., PIETROWSKI, V.; ALVES, L.F.; PINTO JUNIOR, A.S. Biologia da mosca-branca (Bemisia tuberculata Bondar (Hemiptera: Aleyrodidae) em mandioca. Revista Raízes e Amidos Tropicais, v.5, p.265-269, 2009.

SOUZA, L.S.; FARIAS, A.R.N.; MATTOS, P.L.P.; FUKUDA, W.M.G. Aspectos socioeconômicos e agronômicos da mandioca. Cruz das Almas: Embrapa, Mandioca e Fruticultura. 2006. 817p.

TAKAHASHI, M. Cultivo comercial na região centro sul do Brasil. In: CEREDA, M.P. (Org.) Agricultura: Tuberosas amiláceas latino americanas. 1 a ed. São Paulo: Fundação Cargill. 2002. p.258-273.

TAKAHASHI, M.; GONÇALO, S. A cultura da mandioca. $2 a$ ed. Paranavaí: Olímpica. 2005. $116 \mathrm{p}$. 